\title{
ATUAÇÃO DAS OUVIDORIAS PERANTE O CIDADÃO MODERNO
}

\author{
Katherynne Michelynne Cruz Rodrigues ${ }^{1}$
}

\section{Resumo}

A Ouvidoria Pública se firmou como um importante canal de acesso do cidadão brasileiro à Administração Pública. Ela é responsável pelo recebimento de reclamações, denúncias, elogios, solicitações e sugestões que podem se relacionar ao interesse particular do manifestante ou se referir à coletividade. A instituição cresceu em número e em importância nas últimas décadas e está fortemente ligada ao controle social e ao exercício da cidadania. Da mesma forma que a Ouvidoria evoluiu o cidadão também o fez. Hoje o que se vê é um cidadão mais consciente de seus direitos e mais participativo. A era do cidadão passivo, que encarava os serviços públicos como favores do Estado, ficou para trás. Diante disso, a Ouvidoria precisa encarar os desafios e atualizar sua forma de trabalhar, ficando preparada para interagir com o cidadão moderno.

Palavras-chave: Ouvidoria Pública. Cidadão Moderno. Controle Social. Cidadania.

1 Gestora de regulação de serviços públicos lotada na Ouvidoria da Arsae-MG. Graduada em Nutrição pela Universidade Federal dos Vales do Jequitinhonha e Mucuri. Graduanda em Direito pela Universidade Estácio de Sá. (katherynne.mcr@gmail.com) 


\begin{abstract}
The Public Ombudsman's Office was established as an important access channel for Brazilian citizens to the Public Administration. It is responsible for receiving complaints, denunciations, compliments, requests and suggestions that may relate to the particular interest of the protester or refer to the collectivity. The institution has grown in number and importance in the last decades, being strongly linked to social control and the exercise of citizenship. In the same way that the Ombudsman evolved, so did the citizen. Today what you see is a citizen who is more aware of his rights and more participatory. The time of the passive citizen, who thought public services were favors of the state, was left behind. With this, the Ombudsman must face the challenges and update the way they work, being prepared to interact with the modern citizen.
\end{abstract}

Keywords: Public Ombudsman. Modern Citizen. Social Control. Citizenship. 


\section{INTRODUÇÃO}

A redemocratização, ocorrida na década de 1980, criou condições para o exercício do controle social e da participação nas políticas públicas, por meio de diversas instâncias e mecanismos de participação social (MENEZES, 2017). A Ouvidoria Pública é um desses instrumentos que garante que os cidadãos possam levar ao conhecimento da Administração Pública seus anseios e insatisfações e surge com a função de reduzir a distância entre governantes e governados.

O Estado de Direito trouxe uma demanda objetiva por uma Administração Pública honesta, transparente e democrática, na qual os valores da democracia e da cidadania encontram-se bem enraizados (MADRIGAL, 2016). A sociedade pós-redemocratização compreende que exercer a cidadania vai além do ato de eleger seus representantes.

O cidadão moderno é mais atuante na vida pública, quer exercer seu direito de participação e já compreende que para isso precisa estar bem informado. Ele deseja exercer o controle social e receber um serviço de qualidade, pois sabe que o Estado não está lhe prestando um favor, porquanto os órgãos públicos foram criados para servir à sociedade (BRASIL, 2017). Na análise de RICHE (2010), a Ouvidoria Pública "dá à sociedade a oportunidade de conhecer, reconhecer e exigir a prestação de serviços públicos que devem estar, permanentemente, à sua disposição".

Discutir a relação entre esses dois atores em extremos opostos é urgente. Por isso, este artigo se dispõe a analisar o cidadão que se relaciona com a Administração Pública e os desafios que a Ouvidoria enfrenta para se adequar à nova realidade.

\section{DESENVOLVIMENTO}

\subsection{Ouvidorias no Brasil}

As Ouvidorias são instâncias de participação e controle social, nas quais os cidadãos podem registrar suas reclamações, denúncias, solicitações, sugestões e elogios referentes às políticas e aos serviços públicos (BRASIL, 2015). No Brasil, a Ouvidoria Pública, como vista hoje, é uma instituição relativamente nova, que começou a ser delineada na Constituição Federal de 1988. MORAES et al. (2010), em uma análise da evolução histórica das Ouvidorias desde o Brasil-Colônia, relata que a figura do Ombudsman/Ouvidor está presente no país desde esse período. Afirma o mesmo autor que a primeira Ouvidoria Pública no Brasil foi criada na cidade de Curitiba-PR, pelo Decreto-lei $n^{\circ}$. 215/86, e tinha como principal atribuição a defesa dos interesses legitimamente protegidos dos seus cidadãos.

Segundo SANTOS (2017), apesar de a Constituição não trazer expressamente a instituição das Ouvidorias, ela o faz de forma indireta em seu art. 37 , § 3, inciso I, ao preconizar o direito de reclamação.

$\S 3^{\circ}$ A lei disciplinará as formas de participação do usuário na Administração Pública direta e indireta, regulando especialmente: 
I - as reclamações relativas à prestação dos serviços públicos em geral, asseguradas a manutenção de serviços de atendimento ao usuário e a avaliação periódica, externa e interna, da qualidade dos serviços. (CONSTITUIÇÃO FEDERAL DE 1988)

Mais de duas décadas se passaram até que o instituto ganhasse uma definição legal. A conceituação de Ouvidoria coube ao Decreto $n^{\circ} 8.243$, de 2014 , no art. $2^{\circ}$, inciso V, que considera Ouvidoria Pública:

Instância de controle e participação social responsável pelo tratamento das reclamações, solicitações, denúncias, sugestões e elogios relativos às políticas e aos serviços públicos, prestados sob qualquer forma ou regime, com vistas ao aprimoramento da gestão pública.

MENEZES (2017) discorre que a Ouvidoria "assume um papel de extrema relevância para a valorização da cidadania, na condição de instância de promoção e defesa de direitos, viabilizando a participação e o controle social e assegurando o fim público da ação administrativa".

Desde a redemocratização, que foi concluída em 1985, os poderes Legislativo, Executivo e Judiciário vêm criando suas Ouvidorias nos âmbitos federal, estadual e municipal. O maior número de Ouvidorias fortalece a participação social a partir do momento em que elas se firmam como canal que funciona de portas abertas para ouvir a sociedade.

\subsection{Cidadão Moderno}

Com a retomada da democracia, a Constituição de 1988 buscou assegurar em seu bojo que a sociedade pudesse exercer livremente a cidadania. MADRIGAL (2016) entende que a cidadania é um processo que se efetiva através do conhecimento e que está em permanente construção. $O$ cidadão deve conhecer seus direitos, ter consciência de seus deveres e saber que, como parte da comunidade em que vive, ele pode intervir na vida pública.

Hoje, não se pode falar em gestão pública eficaz sem levar em conta os direitos fundamentais e sociais assegurados constitucionalmente e o permanente diálogo entre a sociedade e o Estado (SERRA; CARVALHO; CARNEIRO, 2012). O cidadão atual é mais exigente, participativo e não aceita ser marginalizado das decisões políticas. Ele quer ser ouvido nas instituições públicas e ter o direito de influenciar os rumos das políticas públicas e a qualidade dos serviços recebidos.

Pode-se dizer que o cidadão está mais consciente da sua posição diante da coisa pública em dois eixos principais: como financiador, pois ele contribui financeiramente para o custeio das atividades estatais, e como usuário ou beneficiário dos serviços públicos (SANTOS, 2017).

A sociedade dispõe atualmente de inúmeras formas de entrar em contato com a Administração Pública. Dentre esses canais podemos citar: agências de atendimento presencial, telefonia gratuita, sites institucionais, correios eletrônicos, cartas, entre outros. O Estado se mostra aberto a receber as demandas da sociedade e busca disponibilizar uma gama variada de meios, de forma a atingir os diversos perfis presentes na sociedade.

Com o amadurecimento da consciência cidadã, a democracia participativa é consolidada quando o cidadão utiliza todas as possibilidades participativas expressas na legislação e por meio delas 
amplia o dever de os governantes escutarem a sociedade e prestarem contas de suas gestões (LOCK, 2004).

\subsection{Controle Social}

Nos tempos atuais o cidadão entende sua força na sociedade e exerce seu poder de influenciar a atuação pública por meio do controle social. MORAES et al. (2010) assim descreve o controle social:

O controle social é um termo designado dentro das políticas públicas como uma forma de participação democrática nos processos de gestão das instituições/organizações no Brasil. O controle social se caracteriza pela participação da sociedade nas funções de planejamento, monitoramento, acompanhamento e avaliação de resultados das políticas públicas.

O conceito de accountability veio fortalecer o controle social, ao prever a responsabilização dos agentes públicos pelo mau uso ou gestão da coisa pública. Para SERRA, CARVALHO e CARNEIRO (2012), accountability é valor de responsabilização decorrente da representação. É a imposição de responsabilidades, tornando-se o agente sujeito à consequência de atos próprios ou alheios. Dessa forma, o cidadão pode representar perante a Administração Pública denunciando ações irregulares ou ilícitas.

Segundo CARDOSO, ALCANTARA e LIMA NETO (2013), o Estado brasileiro precisa incorporar os novos atores sociais que surgiram "sob pena de comprometer a legitimidade e, consequentemente, a governabilidade, ou seja, o exercício do poder". Nesse âmbito, as Ouvidorias se destacam como instrumentos de controle social ao propiciar que o cidadão acompanhe e avalie os serviços que Ihe são prestados pelo Estado. A atuação das Ouvidorias pode trazer mais qualidade aos serviços públicos, pois elas são capazes de perceber a insatisfação dos usuários por meio das manifestações recebidas.

\subsection{Desafios Atuais Enfrentados pelas Ouvidorias}

$\mathrm{Na}$ era de um cidadão mais participativo e ciente dos seus direitos, as Ouvidorias enfrentam desafios que carecem ser debatidos e confrontados de forma a tornar o atendimento cada vez mais satisfatório.

Um dos desafios que a Ouvidoria Pública vem encarando é a relação do cidadão com as mídias sociais e os meios de comunicação. Nos tempos da web 3.0 a Ouvidoria necessita preparar-se para lidar com um cidadão que busca respostas de forma tempestiva e não se contenta com respostas que, apesar de estarem no prazo legal, demoram dias para serem disponibilizadas.

A qualificação do atendimento é outro ponto a ser focalizado. O atendente de Ouvidoria precisa ser um profissional treinado e qualificado para estar ali. Segundo BRASIL (2015), o atendente deve identificar a necessidade do cidadão, atenuar a burocracia, ter empatia, cortesia e presteza. 
Esse é um grande desafio, visto que, em alguns órgãos, o desenho estrutural da Ouvidoria não leva isso em conta, sendo o atendimento delegado a profissionais não capacitados para tal. Diversas instituições, entre elas a $A B O$ Nacional, oferecem cursos de capacitação para os profissionais de Ouvidoria, contudo cabe aos órgãos propiciar que seus funcionários sejam capacitados.

Diante do cidadão moderno, que coloca uma carga emocional na sua manifestação, a Ouvidoria necessita também humanizar o atendimento. De acordo com BRASIL (2015), toda vez que a manifestação é acolhida levando em consideração apenas o ponto de vista técnico, sem observar as angústias, temores e expectativas do cidadão, o atendimento está sendo "desumano".

Consoante RICHE (2010), a Ouvidoria precisa aprender a lidar com a manifestação do cidadão e transformar a cultura de reclamação em cultura de cooperação e participação. Para a autora, a Ouvidoria "deve ser um espaço acolhedor, de compreensão, de valorização do ser humano, buscando construir pontes e abrindo novos horizontes, para a reflexão e para o diálogo".

Os canais de atendimento disponibilizados devem ser variados e de fácil acesso, sem exigências desnecessárias ao cidadão. Nesse sentido, a Lei 13.460 de 2017 facilita a apresentação das manifestações e sinaliza que mesmo a falta formal de uma Ouvidoria não é impedimento para o registro da manifestação.

Art. $10, \S 1^{\circ} \mathrm{A}$ identificação do requerente não conterá exigências que inviabilizem sua manifestação.

$\S 2^{\circ}$ São vedadas quaisquer exigências relativas aos motivos determinantes da apresentação de manifestações perante a Ouvidoria.

$\S 3^{\circ}$ Caso não haja Ouvidoria, o usuário poderá apresentar manifestações diretamente ao órgão ou entidade responsável pela execução do serviço e ao órgão ou entidade a que se subordinem ou se vinculem.

As Ouvidorias não são o canal prioritário de atendimento ao público, devendo ser procuradas nos casos de esgotamento das possibilidades de atendimento ou solução pelas áreas competentes. O serviço não é prestado pela Ouvidoria, ela atua como órgão de auxílio ao usuário na resolução de problemas com a Administração (MANUAL OGE MG, 2015). Contudo, quando o usuário chega até a Ouvidoria sem conseguir êxito nos canais anteriores, ele anseia por uma resposta conclusiva. Nesse ponto, a Ouvidoria precisa buscar uma resposta que satisfaça, que atenda à solicitação e, nisso, ela esbarra na baixa autonomia do Ouvidor. A pouca autonomia para mobilizar as áreas necessárias e dar uma rápida solução à manifestação é uma grande barreira a ser vencida dentro das instituições públicas.

SERRA, CARVALHO e CARNEIRO (2012) declaram que o Ouvidor e sua equipe devem ter sua atuação pautada pela probidade, ética, correção, além de possuir independência e autonomia para o desempenho de suas funções. O Ouvidor também precisa ter habilidade para a mediação, pois ele contribuirá para a solução de conflitos envolvendo o cidadão e o gestor. Outra característica fundamental, discorre o autor, é a necessidade de comunicação eficaz, com a correta compreensão das informações trazidas pela sociedade.

Em tempos de um maior número de vias de acesso, o cidadão às vezes recorre a mais de uma Ouvidoria na ânsia de resolver rapidamente o seu problema. Todavia, nesse ponto, a Administração Pública peca novamente. $\mathrm{O}$ isolamento entre as Ouvidorias, pelo qual cada uma atua restritamente 
relacionada à sua instituição, faz com que elas percam força, pois deixam de considerar as correlações de poder com outras instituições e com os setores da sociedade (CARDOSO; ALCANTARA; LIMA NETO, 2013).

A Lei n' 13.460 de 2017 estabelece que todas as manifestações recebidas na Ouvidoria devem ser respondidas. Apesar de parecer uma coisa básica, nem todas as Ouvidorias trabalham assim e carecem de adequação. Na mesma linha, diversos dispositivos legais trazem a obrigatoriedade do fornecimento de protocolo de atendimento. O cidadão atual tem conhecimento desses direitos e, através do protocolo, faz o acompanhamento de sua demanda e reivindica uma resposta.

A elaboração de relatórios em linguagem acessível e que traga as atividades desenvolvidas pela Ouvidoria deve ser colocada em pauta. MENEZES (2017), no Projeto Coleta OGU 2014, que analisou dados sobre Ouvidorias federais no ano de 2014 , relatou que apenas $40 \%$ delas divulgavam seus relatórios periodicamente na web. Isso é um entrave, pois, amparado, entre outras, pela Lei de Acesso a Informação, o cidadão tem direito de acessar as informações produzidas pelos órgãos e entidades públicas.

Por fim, pode-se considerar que o pouco poder da Ouvidoria dentro da instituição é um dos principais desafios, pois impacta diretamente os itens abordados anteriormente. MENEZES (2017), em pesquisa realizada em 2014, aponta como dificuldades enfrentadas pelas Ouvidorias a falta de interesse da alta administração para as questões de Ouvidoria, a escassez de recursos financeiros, as estruturas físicas insuficientes e o déficit no quadro de pessoal. Dessa forma, mesmo que a Ouvidoria enfrente os desafios anteriormente descritos, ela ainda terá dificuldades em efetivar a participação social e aperfeiçoar o serviço público. A Ouvidoria serve como termômetro da satisfação dos cidadãos com os serviços e políticas públicas e, quando há um grande número de manifestações sobre determinado assunto, significa que algo está errado e precisa ser corrigido (BRASIL, 2017). Apesar disso, são poucos os casos em que a autoridade máxima da instituição utiliza os registros da Ouvidoria para detectar a insatisfação geral em meio a demandas individuais e agir previamente em prol da coletividade.

LYRA (2016) defende que o sucesso no desempenho da Ouvidoria "depende, sobretudo, da autonomia do Ouvidor, de sua competência política e de sua imersão na práxis democrática e cidadã". Para o autor, o Brasil vive "uma democracia participativa para inglês ver, com Ouvidorias subordinadas, que pretendem o que não podem ser: sem legitimação democrática, querendo atuar como uma ferramenta idônea da democracia participativa".

\section{CONSIDERAÇÕES}

Como visto, a Ouvidoria Pública avançou nas últimas décadas e se concretizou como uma ponte entre o cidadão e a Administração Pública. Todavia, é inevitável que a instituição atualize sua forma de atuação buscando estar alinhada com a sociedade e atender às expectativas de um cidadão bem mais consciente de seus direitos em face da coisa pública.

O cidadão moderno tem avançado no exercício do controle social, atuando ativamente no controle e fiscalização da coisa pública para obter serviços com maior qualidade e eficácia. A Ouvidoria, 
como importante conquista democrática, precisa acolher esse cidadão e buscar garantir que o exercício da cidadania seja exercido livremente por ele.

Adequar-se ao novo perfil de cidadão, preparando-se para receber manifestações que não objetivem apenas resolver um problema momentâneo, mas que busquem mudar definitivamente uma insatisfação social, pode não parecer tarefa simples, mas necessita ser feito. Cada Ouvidoria deve fazer uma análise de quais desafios demandam um enfrentamento mais rápido e adaptar-se à nova realidade.

\section{REFERÊNCIAS}

BRASIL. Constituição da República Federativa do Brasil. Brasília, DF. Disponível em: <http://www.planalto.gov.br/ ccivil_03/constituicao/constituicaocompilado.htm>. Acesso em: 10 mar. 2018.

CONTROLADORIA-GERAL DA UNIÃO. Manual de Ouvidoria Pública: rumo ao sistema participativo. Brasília, 2015. Disponível em: <http://www.Ouvidorias.gov.br/Ouvidorias/orientacoes/manual-de-Ouvidoria-publica.pdf> Acesso em: 08 abr. 2018.

OUVIDORIA-GERAL DA UNIÃO. Guia prático da cidadania: Falando com a Administração Pública. 2017. Disponível em: < http://www.Ouvidorias.gov.br/central-de-conteudos/biblioteca/arquivos/cartilha-cidada-completa.pdf/ view>. Acesso em: 08 abr. 2018

Decreto 8.243/14, de 23 de maio de 2014. Disponível em: <http://www.planalto.gov.br/ccivil_03/_ato20112014/2014/decreto/d8243.htm>. Acesso em: 24 abr. 2018.

Lei $n^{\circ}$ 13.460, de 26 de junho de 2017. Disponível em: <http://www.planalto.gov.br/ccivil_03/_ato20152018/2017/lei/L13460.htm>. Acesso em: 13 fev. 2018.

CARDOSO, A. S. R.; ALCANTARA, E. L. C.; LIMA NETO, F. C. Ouvidoria Pública e Governança Democrática. Boletim de Análise Político-Institucional. IPEA, Brasília, 2013. Disponível em: <http://www.cgu.gov.br/sobre/institucional/ eventos/anos-anteriores/2013/3a-reuniao-geral-normatizacao-do-sistema-federal-de-Ouvidorias/arquivos/artigo_Ouvidoria-publica_antonio-rito.pdf>. Acesso em: 20 fev. 2018.

GOVERNO DE MINAS. OUVIDORIA-GERAL. Ouvidoria Pública Passo a Passo: Manual de criação, aperfeiçoamento e boas práticas. MG. 2015. Disponível em: <http://fnou.com.br/mwginternal/de5fs23hu73ds/progress?id=IFRE7p7gLAIC_e3p8kcnmdZkcLFqEv8OFQA790-Xoos>. Acesso em: 05 jan. 2017.

LOCK, F. N. Participação Popular no Controle da Administração Pública: Um Estudo Exploratório. Revista Eletrônica de Contabilidade, v. 1, n. 1, 2004. Disponível em: < https://periodicos.ufsm.br/contabilidade/article/download/122/3530>. Acesso em: 21 jun. 2018.

LYRA, R. P. Paradigmas da Ouvidoria Pública e proposta de mudança. In: CARDOSO, Antonio Semeraro Rito; MENEZES, Ronald do Amaral (Org.). Ouvidoria Pública e governança democrática. Brasília: Instituto de Pesquisas Ecônomicas e Sociais (IPEA), 2016. p. 103-132. Disponível em: < http://www.ipea.gov.br/agencia/images/stories/ PDFs/livros/livros/160525_livro_Ouvidoria_capitulo_05.pdf > Acesso em: 21 jun. 2018.

MADRIGAL, A. O exercício da cidadania no desenvolvimento da sociedade. Revista Jus Navigandi. ISSN 15184862. Teresina, ano 21, n. 4673, 2016. Disponível em: <https://jus.com.br/artigos/48124>. Acesso em: 08 abr. 2018.

MENEZES, R. A. A atuação das Ouvidorias Públicas federais como instâncias de controle e participação social no Brasil. 2017. IPEA. Disponível em: <http://repositorio.ipea.gov.br/bitstream/11058/7715/1/td_2286.pdf>. Acesso em: 13 fev. 2018.

MORAES, D.; CRUZ, A.; SILVEIRA, F.; FERLA, A. A Ouvidoria como um processo democrático: sua história e experiência no Pará. Belém, PA. 2010. Disponível em: <http://www.sead.pa.gov.br/sites/default/files/OuvidoriacomoprocessodemocraticohistoriadasOuvidorias.pdf>. Acesso em: 15 dez. 2016.

RICHE, C. A. Ouvidoria, caminho para a civilidade e diálogo. São Paulo: Organicom, ano 7, n. 12, p. 180-182, 2010. 
SANTOS, M. M. Ouvidoria Pública como instrumento de participação social e função essencial à gestão pública moderna. Revista Científica da ABO, v. 1, 2017. Disponível em: <http://www.abonacional.org.br/files/revista-abo-ano1-n1-2017-2018.pdf>. Acesso em: 08 fev. 2018.

SERRA, R. C.; CARVALHO, J. R.; CARNEIRO, R. Accountability democrática e as Ouvidorias. Revista do Tribunal de Contas do Estado de Minas Gerais, v. 30, 2012. Disponível em: <http://revista1.tce.mg.gov.br/Content/Upload/Materia/1684.pdf>. Acesso em: 13 maio 2018. 